\title{
FANTASIA E IDEOLOGIA: REFLEXÃO SOBRE A RECRIAÇÃO DE TRÊS CONTOS DE FADAS PELA DISNEY
}

\author{
FANTASY AND IDEOLOGY: REFLECTION ON THE RECREATION OF THREE FAIRY \\ TALES BY DISNEY
}

\section{Daniela Rebello Pereira Sylvestre ${ }^{1}$}

RESUMO: O artigo defende a relevância dos contos de fadas para a formação integral da criança. Delimitamos três objetos específicos: A Branca de Neve, A Bela Adormecida de Jacob e Wilhelm Grimm e Cinderela de Charles Perrault e suas adaptações cinematográficas (recriações) da Disney. Abordaremos o conceito de conto de fadas, por Nelly Novaes Coelho. Refletiremos sobre os atos de leitura de Barthes, Iser e Jauss. Discutiremos sobre a divulgação dos contos, atualmente, ocorrer pela Disney + Brasil e por fim, concluiremos que a leitura continua sendo uma experiência profundamente pessoal e resultará da permanente confrontação entre a narrativa do autor ou diretor e as histórias das vivências do leitor, que sempre será um coautor da obra.

Palavra-chave: Literatura infanto-juvenil. Cinema. leitor.

ABSTRACT: The article defends the relevance of fairy tales for the integral formation of the child. We delimited three specific objects: Snow White, Sleeping Beauty by Jacob and Wilhelm Grimm and Cinderella by Charles Perrault and its film adaptations (recreations) by Disney. We will discuss the concept of fairy tale, by Nelly Novaes Coelho. We will reflect on the reading acts of Barthes, Iser and Jauss. We will discuss about the dissemination of the stories currently taking place by Disney + Brasil and finally, we will conclude that reading remains a deeply personal experience and will result from the permanent confrontation between the author or director's narrative and the stories of the reader's experiences, which always will be a co-author of the work.

Keyword: Children's Literature. Movie theater. Reader.

\section{INTRODUÇÃO}

A discussão enfocará a questão de a divulgação destes contos atualmente ocorrer de forma mais intensa através dos filmes e a partir de setembro de 2020 do serviço de streaming de vídeo on-line Disney+ Brasil.

Desde já, deixaremos claro que como questão de princípio crítico, rejeitamos a noção de "fidelidade" do filme ao conto, porque são linguagens diferentes e necessitam de meios também diferentes de análise e não é isto que se propõe este estudo.

\footnotetext{
${ }^{1}$ Doc II pela SEEDUC-RJ e SMEC-Magé - Rio de Janeiro https://orcid.org/oooo-ooo3-0521-3024
} 
Nossa proposta tem como objetivo apresentar de que modo as duas linguagens: verbal e visual, como fenômenos culturais articulam-se com a sociedade que as produz e consome.

Primeiramente, discutiremos do ponto de vista teórico o conceito do gênero conto de fadas. Dada a discussão, em torno desse gênero, elegemos o conceito de Nelly Novaes Coelho para trabalharmos. Segundo ela, o conto de fadas é uma área do conto maravilhoso tradicional com a presença de fadas e/ou bruxas, estereótipos do Bem e do Mal, respectivamente.

Em seguida, faremos uma síntese de reflexões sobre os atos de leitura, consideraremos os conceitos de Roland Barthes, Wolfgang Iser e Hans Robert Jauss. Ampliaremos essa noção de leitor de uma obra escrita a leitor de filme, até porque ambos são formas de linguagens e por isso possuem vazios que serão preenchidos pela inventividade do leitor.

Esta intenção, pode ser comprovada pela citação de W. Iser de que um ponto central na questão da leitura de qualquer texto, seja literário ou não, é a interação entre sua estrutura e o receptor.

Defenderemos que apesar do filme e do livro se imporem ao leitor, principalmente o primeiro, com suas imagens visuais e sons, a leitura continua sendo uma experiência profundamente pessoal e resultará da permanente confrontação entre a narrativa do autor ou diretor e as histórias das vivências do leitor, que sempre será um coautor da obra.

Logo, a leitura é um somatório das vivências do leitor, inserido num dado contexto; a sua leitura de mundo, que com certeza influenciará e muito nessa leitura posterior seja de um filme ou livro, portanto, julgamos pertinente considerarmos Paulo Freire nesta pesquisa, que tem um vasto legado sobre a importância do ato de ler o mundo, que precede a leitura da palavra escrita.

A produção, seja de um filme ou um livro, está inserida num contexto histórico e social e estes influenciam na construção daquele, assim como em sua leitura.

Traremos breves considerações sobre a recriação e equivalência dos filmes à literatura. Versaremos sobre a popularidade dos filmes da Disney que pouco se importa com a função dos contos de fadas que personificam e ilustram os conflitos internos das crianças, sugerindo sutilmente como solucioná-los e assegurando um final feliz. A 
indústria cinematográfica norte-americana, num contexto do capitalismo neoliberal, faz do filme uma mercadoria lucrativa.

\section{1- Conto de fadas ou Conto maravilhoso}

A conceituação do gênero contos de fadas é muito polêmica, portanto, optamos por trabalhar com a definição apresentada por Nelly Novaes Coelho.

Segundo ela, de todo caudal narrativo existente, simplificado hoje em dia em literatura folclórica ou infantil, destacam-se duas formas distintas: os contos maravilhosos e os contos de fadas.

Narrativas maravilhosas surgidas de fontes distintas, com problemáticas diferentes, mas que costumam ser identificadas entre si como iguais. Tanto os contos maravilhosos quanto os contos de fadas expressam atitudes humanas, porém diferentes, embora se completem numa realização integral.

No conto de fadas, seus argumentos de desenvolvimento são dentro da mágica feérica (reis, rainhas, príncipes, princesas, fadas, bruxas, gigantes, anões...) e têm como eixo gerador uma problemática existencial.

Já no conto maravilhoso, há narrativas que sem a presença de fadas, desenvolve-se no cotidiano mágico (animais falantes, tempo e espaço reconhecíveis, gênios, duendes, etc.) e têm como eixo gerador uma problemática social, ou ligada à vida prática. Trata-se sempre do desejo de auto realização do herói (ou anti-herói) no âmbito socioeconômico, através da conquista de bens materiais, poder material, etc.

Decorre daí a atualidade incontestável dos contos e sua importância. Ambos expressam atitudes humanas e por temperamento ou personalidade, inconscientemente ou não, um indivíduo opta por uma (ou ambas) para orientar sua luta pela vida.

Então, os contos de fadas, para a autora, são aqueles onde há a presença de fada e/ou bruxa. Sendo assim, os três contos em análise: Branca de neve, A Bela Adormecida e Cinderela são considerados contos de fadas. Em Cinderela de Perrault uma fada madrinha lhe proporciona uma carruagem, lacaios e lindas roupas; em Branca de Neve dos Irmãos Grimm há uma vilã duplamente encarnada, como uma rainha bela, orgulhosa e má como uma bruxa feia e perversa; e em A Bela Adormecida também dos Grimm há a presença das feiticeiras do reino. 
Em seu livro Psicanálise dos contos de fadas, Bruno Bettelheim explica que as fadas como mediadoras mágicas torna possível a concretização de sonhos, das aspirações, da fantasia, imaginação etc. do homem em situações onde nenhuma solução natural ajudaria.

Estou, mas será que vou assim, tão maltrapilha? Bastou que a madrinha a tocasse com sua varinha, e no mesmo instante suas roupas foram transformadas em trajes de brocado de ouro e prata inscrustados de pedraria. Depois ela the deu um par de sapatinhos de vidro, os mais lindos do mundo (Perrault apud Tatar, 2004: 43).

E as bruxas ao contrário, também dotadas de poderes sobrenaturais, interferem na vida do homem para prejudicá-lo, têm um comportamento negativo, como a de Branca de Neve: "Quando a rainha ouviu estas palavras, o sangue gelou suas veias...Usando toda a bruxaria que conhecia, fabricou um pente envenenado"(Perrault apud Tatar, 2004: 94).

Ela desempenha o lado destrutivo do princípio arquétipo feminino, o princípio da morte, da doença, da desintegração, ou ainda, daquilo que se poderia chamar de maléfico da inconsciência. Elas em geral, intrigam, envenenam, matam ou comem gente, caluniam pessoas para que briguem umas com as outras.

Para Bettelheim (2009:I19) esses seres imaginários dotados de poder expressam os desejos do homem, de forma irrealista, a fada e a feiticeira são sobre humanamente recompensadas e a bruxa é desumanamente destrutiva.

Representantes dos arquétipo feminino,

As fadas simbolizariam talvez a face positiva e luminosa dessa força feminina $e$ essencial: o seu poder de dispor da Vida, de conter em si o futuro (Lembremo-nos que o principal missão das fadas nas estórias infantis, é prever o futuro de algum ser). O reverso seria a face frustradora: a da bruxa-mulher que corta o fio do destino, frustra a realização do ser (Bettelheim, 2009:125).

\section{2- $\quad$ Refletindo a leitura}

Hans Robert Jauss formulou uma estética do leitor, valorizou sua percepção estética, fornecendo-lhe um lugar significativo no estudo da teoria literária.

Compreendendo que a obra está presente na história, isto é, no horizonte histórico de sua origem, função social e ação histórica, quer avaliar a evolução dos modos de recepção da obra através do tempo.

Assim, relaciona o leitor à sua época, sua integração à história, determinando a apreensão dos fatos culturais e situando-os no tempo. 
A obra possui então, para ele, historicidade, porque se transforma e evolui, seu objetivo é compreender como a obra modifica-se devido à emergência de novos horizontes e como ela atualiza-se e rejuvenesce no decurso do tempo.

Segundo Jauss, é a percepção do leitor que atualiza a obra no tempo, mas, é a obra em si que favorece esta renovação permanente porque contém "indícios de liberação e conhecimento" (Lajolo e Zilberman, 2019). Todavia, estes indícios nem sempre são os mesmos, já que são identificados dependendo do contexto histórico-social de uma dada época.

Wolfgang Iser procura compreender a interação entre texto e o leitor individual e a experiência que isto provoca: a experiência literária.

Entende que o texto é lido de diversas maneiras e que sem este ato de leitura o texto não realiza seu potencial. Portanto, necessita do leitor, é ele quem aceita ou rejeita o jogo do texto que com sua estrutura convoca uma atitude participativa do leitor.

O leitor entra no universo ficcional através das lacunas, vazios do texto e preencheos com sua imaginação e criatividade.

É por essa razão que um "mesmo" conto é interpretado de diversas maneiras, porque cada leitor é único e tem experiências também únicas.

São nesses vazios do texto que entra a "leitura de mundo" do leitor que nos ensinou Paulo Freire.

A temática da leitura segundo Freire abrange não apenas o texto, mas também o contexto. A criança não aprende a ler somente quando é alfabetizada, muito antes disso, ela já é capaz de ler.

Ler para ele é interpretar as coisas do mundo, do contexto onde vive. O texto, a palavra, as letras podem ser o canto dos pássaros; a cor do céu, com suas nuvens, movimentos; o cheiro das flores; a observação das reações dos animais.

São essas leituras, juntamente com o universo dos adultos, que expressam suas crenças, gostos, receios e valores, ligando-se a contextos mais amplos como os problemas socioeconômicos de sua cidade, país, etc. que formam a bagagem cultural de cada um. E é a bagagem, com toda a leitura de mundo que cada um carrega consigo que influencia na sua leitura.

Quando uma pessoa assiste a um filme ou um livro, ela constrói seu sentido. 
Afirmamos que o leitor constrói o sentido do texto porque concordamos com Roland Barthes que afirma que não existe um certo sentido da obra, o verdadeiro sentido, tão pouco o que o autor quis dizer. Sendo esse sentido dado pelo próprio leitor, no momento de sua leitura; este constrói o texto associando a "cada uma das frases, outras ideias, outras imagens, outras significações.” Segundo ele “...o texto sozinho é uma coisa que não existe: há imediatamente nesta novela, neste romance, neste poema que leio, um suplemento sentido, de que nem o dicionário nem a gramática são capazes de dar conta" (Barthes, 2006: 28).

É o leitor, como já foi dito, que constrói o sentido da obra, devido a sua ideologia (onde entra a sua bagagem cultural e imaginação) e a fatores extralinguísticos, em que a circunstância ou contexto influencia o sentido dado pelo leitor.

No entanto, ler um texto não é somente interpretá-lo livremente, por mais que essa bagagem cultural influa nesta interpretação, o texto (obra) sempre acrescenta algum conhecimento ao leitor, é uma relação de troca. E nesta relação, a obra (por ser veículo de expressão ideológica) pode incutir no leitor valores pertinentes ao espaço social e tempo histórico na qual se insere.

Como afirmamos que o contexto histórico e social influencia no sentido que o leitor dá a obra.

\section{3- $\quad$ Breve panorama histórico dos contos de fadas}

Os primeiros registros de contos de fadas deram-se durante o século XVII em plena era do Absolutismo e Classicismo na França.

Construídos a partir de textos da Antiguidade Clássica ou de narrativas que viviam oralmente entre o povo, a literatura destinada às crianças ou jovens, tinha o intuito de educá-las no princípio humanista. Temos As fábulas (1698) de La Fontaine; os Contos de Mãe Gansa (1691/1697) de Charles Perrault; os Contos de fadas (8vols. 1696/1699) e Mme. D’Aulmoy e Telêmaco de Fénelon (Coelho, 1985:56).

Perrault tentava educar através da moral que punha ao final de todos os seus contos.

“Nessa 'moralidade' bem utilitarista, está evidente uma das realidades da época: a superioridade do burguês, 'industrioso e trabalhador', que trabalha, realiza e conquista... em relação ao nobre que herda, nada faz e acaba por perder a fortuna herdada"(Coelho, 2000). 
No final do século XVIII (1785-1789) sai a publicação de Gabinete de Fadas (4I volumes de vários autores de contos de fadas e outros contos maravilhosos) que marcam o fim dessa produção literária fantástica.

Com a eclosão da revolução Francesa em 1789 e com o novo sentimento e a nova Razão implantada, as fadas passaram a segundo plano, embora continuassem presentes nas narrativas orais e nos livros infantis.

Até o século XVIII não havia literatura destinada as crianças porque não existia uma visão especial da infância. Somente no meio à Idade Moderna passou-se a compreender a inf6ancia como uma faixa etária diferenciada, com interesses próprios e necessidades de uma formação específica.

Esta mudança deveu-se a emergência de uma nova noção de família, centrada agora num núcleo unicelular e não mais nas amplas relações de parentesco, a fim da privacidade e impedir a intervenção de parentes em seus negócios e estimular o afeto entre seus membros.

Da metade da Idade Moderna até hoje existiram pelo menos três formas de compreender a infância: A primeira foi da criança vista como um indivíduo que precisa de atenção. As reedições dos contos de fadas que trazem essa concepção, são escritas então com o objetivo de educar e ajudá-las.

Com o advento da Psicologia da Aprendizagem, a infância passa a ser entendida como a etapa de preparação do pensamento para a vida adulta. $O$ pensamento infantil ainda não tem uma lógica racional. A literatura destinada a essa faixa etária é adequada as fases do raciocínio infantil.

A mais nova concepção infantil defende que é preciso entender que a criança é também cheia de conflitos, medos, dúvidas e contradições não por desconhecer a realidade, mas por trazer consigo a imagem projetada do adulto.

A imagem da criança é o reflexo do que o adulto e a sociedade pensam de si mesmos. Esta representação da criança transforma-se aos poucos em realidade e a criança dirige certas exigências ao adulto e à sociedade, em função de suas necessidades essenciais.

A literatura que conceba a infância dessa forma, vai então privilegiar o lado espontâneo, intuitivo, analógico e concreto da natureza humana e ver seu leitor como um ser de desejos e pensamentos próprios. 
Esta literatura investe no literário, enfrentando sua qualidade artística e oferecendo os melhores produtos possíveis ao repertório infantil.

Atualmente, é mais comum as crianças terem acesso ao acervo cultural dos contos de fadas, através dos filmes. Como isto é um fato notório, a seguir trataremos dessa questão, observando as diferenças cabíveis entre as duas obras: conto e filme. Detendo-se mais sobre a divulgação dos filmes, versaremos sobre seus aspectos positivos e negativos, respaldadas nos estados de Bettelheim e Henry Giroux.

\section{4- Leitura e filme: recriação e equivalência}

Haroldo de Campos trabalha com a noção de tradução e crítica. Campos vê duas opções para o cineasta que deseja adaptar um romance: ou ele segue a estória passo a passo e tenta traduzir não a significação das palavras, mas as coisas referidas pelas palavras (e neste caso o filme não é uma expressão criativa autônoma, mas apenas uma representação ou ilustração do romance), ou tenta repensar o assunto na íntegra, dando-lhe outro desenvolvimento e outro sentido.

Os filmes da Disney de contos de fadas são, portanto, recriações e ganharam significância autônoma principalmente através de suas inevitáveis e necessárias divergências da obra original.

A literatura deve ser entendida, a partir de tudo que já foi esboçado, num sentido muito mais amplo que inclui tanto a leitura de um livro quanto de um filme, já que ambas são formas de linguagens.

\footnotetext{
Não surgiu uma linguagem autenticamente nova até que os cineastas começassem a cortar o filme em cenas, até o nascimento da montagem, da edição. Foi aí, na relação invisível de uma cena com a outra, que o cinema realmente gerou uma nova linguagem (Carrière, 2015: 14).
}

Uma óbvia diferença entre as duas obras, é que, predominantemente, o filme é uma comunicação visual e o conto é uma comunicação verbal.

Quase no começo da aventura, os cineastas perceberam que a memória de imagens pode, às vezes, ser mais forte e duradoura do que a de palavras e frases (Carrière, 2015: 2I).

A palavra e a imagem precisam ser reconstruídas internamente, ou percebidas conceitualmente para serem entendidas. Dessa forma, o leitor tem papel fundamental na leitura. Até porque ambas, filme e conto são formas discursivas de comunicação, à medida 
que a imagem quando combinada diacronicamente com outras imagens a sequência resultante é discursiva.

O tempo e o espaço são retratados diferentemente nas duas produções. $O$ tempo no conto é codificado linguisticamente, no filme é com imagens e ações concretas.

No filme, o tempo parece análogo ao tempo real, onde percebemos a ação e o movimento e não o tempo de duração que está situado objetivo e graficamente. Assim, o espaço predomina no filme.

O tempo predomina no conto porque as sucessões dos acontecimentos e o desenvolvimento das personagens dependem dele, ao mesmo tempo em que o constroem. O espaço no conto é conceitual.

Ao adaptar um conto de fadas, o cineasta frequentemente aumenta seu tempo de duração, com inserção de novas cenas e músicas.

No filme, o tempo que o leitor leva para vê-lo normalmente coincide com o do narrador, sendo fixado por convenção numa média de noventa a cento e vinte minutos.

O tempo (de leitura) do leitor pode variar grandemente de narrativa a narrativa dependendo do tamanho do gênero.

Tanto o filme quanto o conto podem diminuir ou aumentar seu tempo de duração. O primeiro pelo uso da câmera lenta ou acelerada e o segundo ao jogar entre o tempo do leitor e o tempo dos eventos narrados.

$O$ cineasta recria em linguagem em linguagem não verbal o que o escritor expressou em linguagem verbal.

Apesar dessas diferenças, ambos são basicamente iguais na capacidade de significar, embora diferentemente, tendem a usar linguagem figurada ou metafórica e como vimos, distorcem o tempo e o espaço.

\section{5- Lucrativo mercado}

Não é de admirar que a fim de assegurar o sucesso econômico devido a um público alvo em potencial (as crianças), muitos cineastas tenham proposto a recriação de contos conhecidos. A maioria das crianças conhece a história de Branca de Neve, Cinderela e A Bela Adormecida. Recriá-los é sucesso quase que na certa.

Com o advento das novas tecnologias digitais de comunicação e informação, a internet popularizou-se bastante e os filmes antes divulgados em VHS e DVD saíram de 
circulação, dando espaço para as plataformas de streaming, onde os filmes infanto-juvenis passaram a ter até maior divulgação, pois ficam disponíveis para o público $24 \mathrm{~h}$. Por isso, a Disney lançou em 2019, um serviço de assinatura de sua própria plataforma de streaming de vídeo on-line: o Disney +. Operado pela Direct-to-Consumer \& International (DTCI) uma subsidiária da The Walt Disney Company. O serviço disponibiliza filmes e séries de televisão produzidos pelos estúdios e Walt Disney Television, com o conteúdo de publicidade das marcas Marvel, National Geografic, Pixar e Star Wars.

Sendo assim, a Disney retirou de todas as outras plataformas seus produtos, garantindo fidelidade dos consumidores e sua lucratividade.

\section{6- A “disneyzação" dos contos de fadas}

Para o crítico Henry Giroux todo o aparato técnico do filme nada mais é do que um veículo de expressão ideológica. Ideologia inclui ideias religiosas, políticas, morais, visões de mundo, atitudes, maneira de pensar e de colocar problemas.

Ao contrário da realidade dura e sem graça, nos filmes, a criança encontra um espaço visual com impressionante tecnologia com magníficos efeitos de som e imagem e, assim, suas simpáticas e amáveis estórias são apresentadas numa atraente embalagem de entretenimento e numa esfera comercial de consumismo.

A legitimidade dos filmes da Disney, para Giroux, se dá em parte devido à crise na educação em geral: as instituições de ensino estão sem rumo, princípios e motivações, assim como a família. E ao contrário de muitos filmes adultos, com filmes infantis não temos análises críticas, o que facilita a imposição de valores na cultura infantil. A pretensa inocência da Disney parece ser uma promoção mascarada para incentivar as crianças a serem consumidores.

Bettelheim é tão rígido quanto Giroux no julgamento de que os filmes da Disney são ruins para as crianças. No entanto, a motivação que os levam a essa conclusão é bastante diferente.

Em seus estudos, Giroux não considera o aspecto psicológico presente nos contos e que segundo Bettelheim, a Disney simplifica nos filmes. Giroux revela apenas a questão ideológica manifestada nos filmes. 
A maioria das crianças agora conhece os contos de fadas só em versões amesquinhadas e simplificadas, que amortecem os significados e roubam-nas de todo o significado mais profundo - versões como as dos filmes e espetáculos de $\mathrm{TV}$, onde os contos de fadas são transformados em diversão vazia. (Bettelheim, 2009: 32)

\section{Conclusão}

Os contos de fadas têm resistido a todas as mudanças pelas quais as sociedades passam. Mudanças estas, de valores, econômicas e sociais, que alteram o conhecimento de mundo e, evidentemente, fazem com que as pessoas criem novas representações de mundo.

É natural que esse processo de evolução, transforme a Literatura (contos de fadas), porque as mudanças dos contos de fadas são ligadas direta ou indiretamente a determinado contexto social e tradição histórica.

Por observação, todos podemos comprovar que o homem tem necessidade do maravilhoso, tanto na literatura adulta quanto na infantil e é por isso que os contos de fadas sobrevivem a todas as transformações.

O filme, assim como o livro, trabalha com a linguagem que estrutura o pensamento, dá corpo as ideias e faz divagar a imaginação; enfim, com o que é privativo ao sujeito, que o distingue dos outros animais.

O conto, além de ser um estímulo ao desenvolvimento intelectual da criança, pode ser um incentivo a leituras posteriores. Há livros específicos para cada idade, assim como filmes, cremos que se esse critério for respeitado, o gosto e o prazer pela leitura, serão criados e preservados por toda a vida.

Logo, a leitura dos contos de fadas: Branca de neve, A Bela Adormecida e Cinderela, contribui e é mesmo fundamental para a formação da criança na condição de leitora de mundo, crítica e consciente.

\section{Referências bibliográficas}

BARTHES, Roland. O rumor da língua. São Paulo: Martins Fontes, 2004. 2 ed.

BETTELHEIM, Bruno. Psicanálise dos contos de fadas. Rio de Janeiro: Paz e Terra, 2009, $37 \mathrm{ed}$.

CARRIÈRE, Jean Claude. A linguagem secreta do cinema. Rio de Janeiro: Nova Fronteira, 2015 . 
COELHO, Nelly Novaes. Literatura Infantil: teoria, análise, didática. São Paulo: Moderna, 2000.

FREIRE, Paulo. A importância do ato de ler: em 3 artigos que se completam. São Paulo: Cortez, 2017.

GIROUX, Henry. Atos impuros: as práticas políticas dos estudos culturais. São Paulo: Penso, 2003.

LAJOLO, Marisa e ZILBERMAN, Regina. A formação da leitura no Brasil. São Paulo: Unesp, 2019.

TATAR, Maria. Conto de fadas edição comentada e ilustrada. Rio de janeiro, 2004. 